\title{
Projection of Geographical Variability and Temporal Trends on Drought Characteristics Using Standardized Precipitation Evapotranspiration Index (SPEI) for Water Resource Management of Critical Zones in Sindh, Pakistan.
}

\author{
Humayoon Sial*, Suhail Ahmed Manganhar** \\ * B.Tech Civil Technology at GCT Khairpur, affiliated with QUEST; humayoonsial.civil@gmail.com. \\ ** U.S.-Pakistan Center for Advanced Studies in Water (USPCAS-W), at Mehran University of Engineering and \\ Technology (MUET) Jamshoro; engrsam1306@gmail.com
}

\begin{abstract}
The recent increase of droughts in Sindh, Pakistan has had a large impact on the economy and environment of the province. Continuous change in patterns of rainfall and hydrological cycles due to climate change can potentially accelerate the occurrence of extravagant droughts and affect the availability of water resources in the future. This alarming situation makes it necessary to evaluate and estimate the vulnerability for planning and management of water resources and identify the well-suited and effective mitigation actions to conduct a risk analysis for droughts. The aim of this research is to identify change in temporal trends of drought characteristics in Sindh province due to climate change. Initially, at the first stage, the changes in appearance and occurrence of droughts were calculated by utilizing the Standardized Precipitation Evapotranspiration Index (SPEI) for Climate research unit (CRU) data of Sindh province and were analyzed for the past 30 years (1902 - 2015), and Representative Concentration Pathways (RCP) climate change situations data of year (2011 - 2099). Second, the variation on the temporal trends of drought properties was carried out by utilizing run theory which was used for comparative analysis of drought total period, extent, severity, and significance to allow for quantitative evaluation under previous and approaching climate conditions. These results determine the severe influence of climate change on drought and will help in the planning and management of water resources and drought countermeasures (physical control, technical control, administrative and managerial control) to climate change.
\end{abstract}

Keywords: water resource management; Climate research unit (CRU); climate change; run theory; Standardized Precipitation Evapotranspiration Index (SPEI); Representative Concentration Pathways $(\mathrm{RCP})$

1. Introduction

Innumerable catastrophes, accelerated by many natural and pollutant reasons, have affected the globe. Every occurring hazard tends to be disastrous when it negatively affects the lives of people and their resources. From every occurring hazard, droughts are prominent as its impact significantly transcends human society. A complex composite of societal and hydrological factors is responsible for the appearance of droughts which makes modeling of this phenomenon radically challenging. Drought is one the major 
natural catastrophe which affects mainly water resources, agriculture productivity, as well as social and economic development factors.

Sindh acts as the hub of agriculture, minerals other natural resources as well as being one of the most significant lands in Pakistan, suffering the most extravagant droughts disaster compared to other provinces.

The Natural Disaster Consortium (NDC) comprised of International Organization for Migration (IOM), Food and Agriculture Organization of United States (FAO), United Nations Children's Fund (UNICEF), Agency of Technical Cooperation and Development (ACTED) and Health and Nutrition Development Society (HANDS) conducted Sindh Droughts Need Assessment (SDNA) in eight districts of Sindh. As reflected in the report the drought adversely impacted the agriculture sector (in terms of area under cultivation, production of crops, and livestock). The less availability of water reported is attributed to no or very less precipitation and persisted dry conditions which are the result of less rainfall and limited or no availability of water or irrigation [1].

From the assessment of Pakistan National Drought Monitoring Centre (PNDMC), it can be clearly observed that extravagant droughts are occurring in most parts of Sindh Province, which is very critical situation for the province. This alarming situation makes it necessary to evaluate and estimate the vulnerability for planning and management of water resources and identify the well-suited and effective mitigation actions to conduct a risk analysis for drought.

Drought's common availability has made it easy to define its existence but still, it is very complex that it cannot be properly defined in terms of quantity. Many researchers have suggested different indices to quantify the droughts by the past years to facilitate quantification and measurement of droughts vulnerability.

In this research, we have used many scientific techniques, equations, coding software to get precise results. Initially, at the first stage, the changes in appearance and occurrence of droughts were calculated by utilizing Standardized Precipitation Evapotranspiration Index (SPEI).

Past 20 years (1991-2010) data was analyzed by extracting CRU Data, and Representative Concentration Pathways (RCP) scenarios for climate change from the year (2011 - 2099).

Then, the variations for temporal trends of drought properties was carried out for comparative analysis of drought total period, extent, and significance for quantitative evaluation for previous and approaching meteorologic conditions.

Calculated results determine severe connections of change in climate on droughts and will add ease in planning and management of water resources and precautions to be made for droughts in advance, that will surely help in calculating optimal supply of water to the consumers.

\section{Study Area and Data Preparation}

\subsection{Study Area}

With a land of almost 140915 Sq km (54407 sq mi), Sindh Province lies in Pakistan in the domain of 26021'N 6851'E, Sindh (Figure 1) lies in the western corner of South Asia. From East it has Thar Desert and Kithar Mountains in West, further in the South it is touching the Arabian Sea. The center of Sindh is fertile plain running with Indus River. Geographically in the Pakistan, Sindh is $3^{\text {rd }}$ largest province, covering about 578 $\mathrm{Sq} \mathrm{km} \mathrm{(360} \mathrm{mi)} \mathrm{from} \mathrm{North} \mathrm{towards} \mathrm{South} \mathrm{and} 443 \mathrm{Sq} \mathrm{km} \mathrm{(275mi)} \mathrm{peak} \mathrm{or} 282 \mathrm{Sq}$ km (175 mi) average from East towards West. 
Sindh Province lies in topical - subtropical regions; its area is very warm in summer and mild in winter. The frequent rise in temperature is above $46^{\circ} \mathrm{C}\left(115^{\circ} \mathrm{F}\right)$ in May to August and minimum common temperature of $2^{\circ} \mathrm{C}\left(36^{\circ} \mathrm{F}\right)$ happens in December to January at northern and peak regions of province [2].

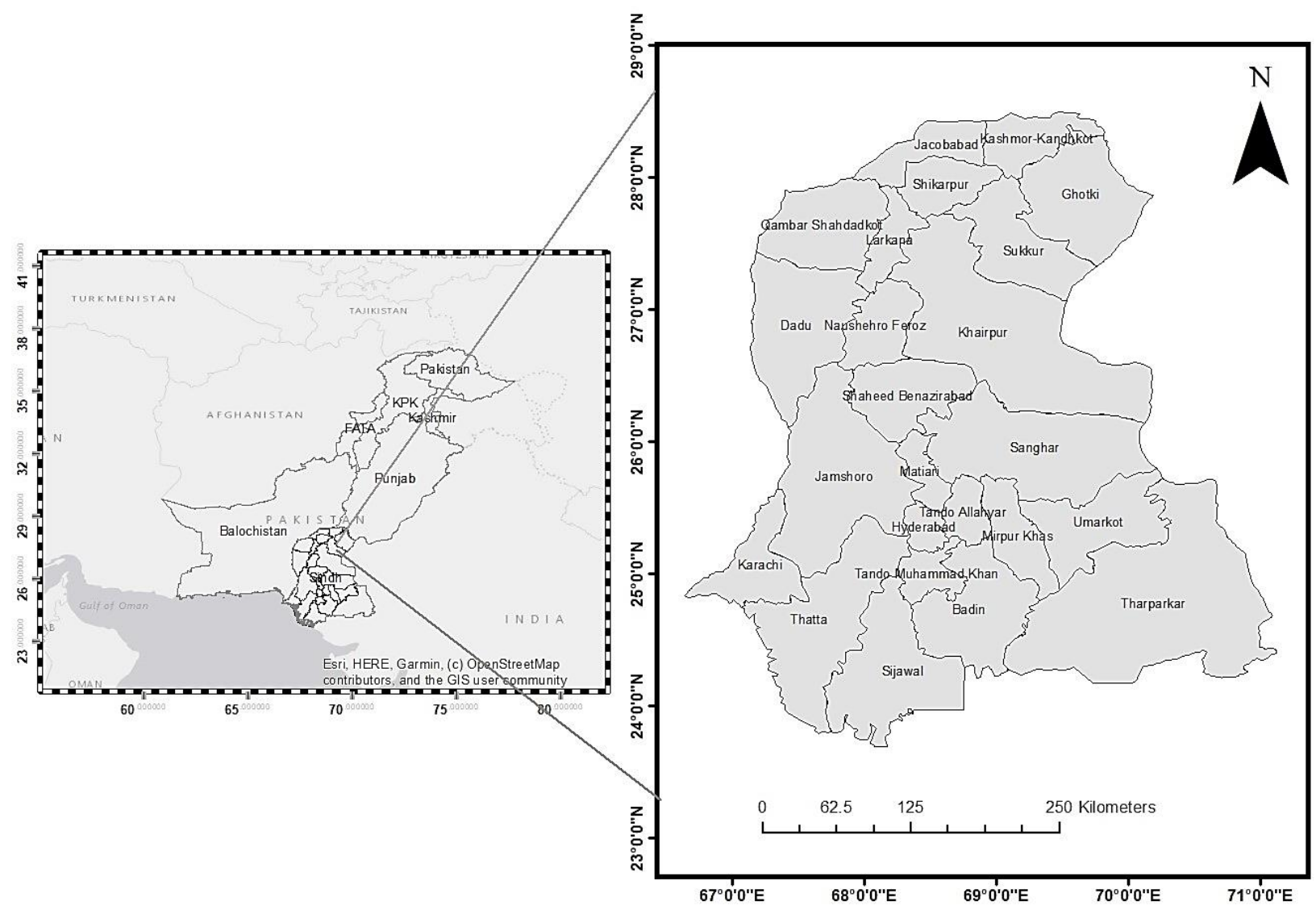

Figure 1

\subsection{Data}

\subsubsection{Historical Data}

Data for Potential Evapotranspiration and Precipitation is extracted from the values provided by Climatic Research Unit (CRU) at the University of East Anglia (CRU TS 3.24). Monthly time series data of variables from 1901 to 2015 is contained in the CRU TS 3.24 dataset at a spatial resolution of $0.5^{\circ}$ by $0.5^{\circ}$ that is nearly $56 \mathrm{~km}$ to equator. The primary source for data includes weather records from many data publications [2].

For the estimation of PET using Penman Monteith, water demand of atmosphere and balance for surface energy were taken into consideration. As SPEI is calculated by the same way as SPI, however, in addition, data for PET is required monthly wise as climate water balance is calculated by SPEI. 


\subsubsection{Future Data}

Average monthly data of temperature and precipitation of ninety years (2010 - 2099) for the province of Sindh was acquired from Numerical Modelling Group of Research and Development Division, Pakistan Metrological Department. The climate change scenario data of RCP 8.5 for Pakistan which is downscaled data established on IPCC (Intergovernmental Panel on Climate Change) Fifth Assessment Report (AR5) [3]. The data is spatially interpolated a $25 \times 25-$ kilometer grid. The calculation of potential evapotranspiration is based on the Blaney Criddle Method [4] due to data limitations.

\section{Methodology:}

\subsection{Standardized Precipitation Evapotranspiration Index (SPEI)}

SPEI requires only data for temperature and precipitation Requiring only precipitation and temperature, which facilitates the researchers to evaluate and design the effects of changes in temperature and its variability on the drought's characteristics. SPEI is also known as enhanced version for SPI, that is why the process of calculations in SPEI is same as it is in SPI.

\subsection{Calculation of Standardized Precipitation Evapotranspiration Index (SPEI)}

Monthly precipitation is needed for the calculation of SPI. However, difference between (PET) and precipitation is must for calculation of SPEI. For calculating SPEI the very first step is the estimation of PET for that many solutions are provided by scientists like Thornthwaite method (Thornthwaite, 1948), Penman-Monteith method and Hargreaves method etc. These methods require different data for calculation, among all Thornthwaite method is simple of all as only monthly temperature is needed [5]. Furthermore, only the relative temporal variability of PET is required for the calculation of drought index which makes the choice of method trivial. After the calculation of PET, the climatic water balance, D, for the month $\mathrm{i}$ is calculated using the equation below.

$D i=P i-P E T i$

The results of D in Equation (i) are calculated at varying temporal scales. SPEI values can be calculated many times by fitting a three-parameter probability assessment. The resultant probability distribution function of the $\mathrm{D}$ series is given by the following formula.

$F(x)=\left[1+\{\alpha /(x-\gamma)\}^{\beta}\right]^{-1}$

The SPEI, then, is the standardized value of $\mathrm{F}(\mathrm{x})$ and is obtained by the approximation of Abramowitz and Stegun (1965) [6] given below.

$S P E I=W-\left(C_{0}+C_{1} W+C_{2} W^{2}\right) /\left(1+d_{1} W+d_{2} W^{2}+d_{3} W^{3}\right)$

Where,

$W=\sqrt{ }-2 \ln (\mathrm{p})$ for $\mathrm{p} \leq 0.5$ 
and $C_{0}, C_{1}, C_{2}, d_{1}$, and $d_{2}$ are constants. $p$ is the probability of exceeding a determined $D$ value, $\mathrm{p}=1-\mathrm{F}(\mathrm{x})$. If $\mathrm{p}>0.5$, then $\mathrm{p}$ is replaced by $1-\mathrm{p}$. The sign of the SPEI is then reversed (Vicente-Serrano, Beguería and López-Moreno, 2010) [7].

So SPEI index, is important for evaluating droughts of many types - due to its multi-scalar character while also incorporating the temporal variability in temperature to reflect the effect of climate change.

\begin{tabular}{|lcc|}
\hline SPEI & Categories & Frequency (\%) \\
\hline $2.0 \leq$ SPEI & Extreme wetness & 2.2 \\
$1.5 \leq$ SPEI $<2.0$ & Severe wetness & 4.4 \\
$1.0 \leq$ SPEI $<1.5$ & Moderate wetness & 9.2 \\
$0.5 \leq \mathrm{SPEI}<1.0$ & Slight wetness & 15.0 \\
$-0.5<\mathrm{SPEI}<0.5$ & Normal & 38.4 \\
$-1.0<\mathrm{SPEI} \leq-0.5$ & Slight dryness & 15.0 \\
$-1.5<\mathrm{SPEI} \leq-1.0$ & Moderate dryness & 9.2 \\
$-2.0<\mathrm{SPEI} \leq-1.5$ & Severe dryness & 4.4 \\
SPEI $\leq-2.0$ & Extreme dryness & 2.2 \\
\hline
\end{tabular}

Figure 2 SPEI Classification

\section{Results and Discussion:}

The droughts temporal analysis alarms long-term drought conditions in the Sindh. The SPEI of 3 months is displayed in Fig 8, also containing trend line. From the graph it period of dryness and wetness can clearly be differentiated. The duration of drought its peak, and drought severity of Sindh is shown in Figs 4-5-6-7.

During the period of research, drought peak in Sindh was above -1.6 as can be seen in Fig g. On the other hand, if w looks at Fig 4, it can be observed that longer period droughts and droughts with high severity occurred in Sindh. 


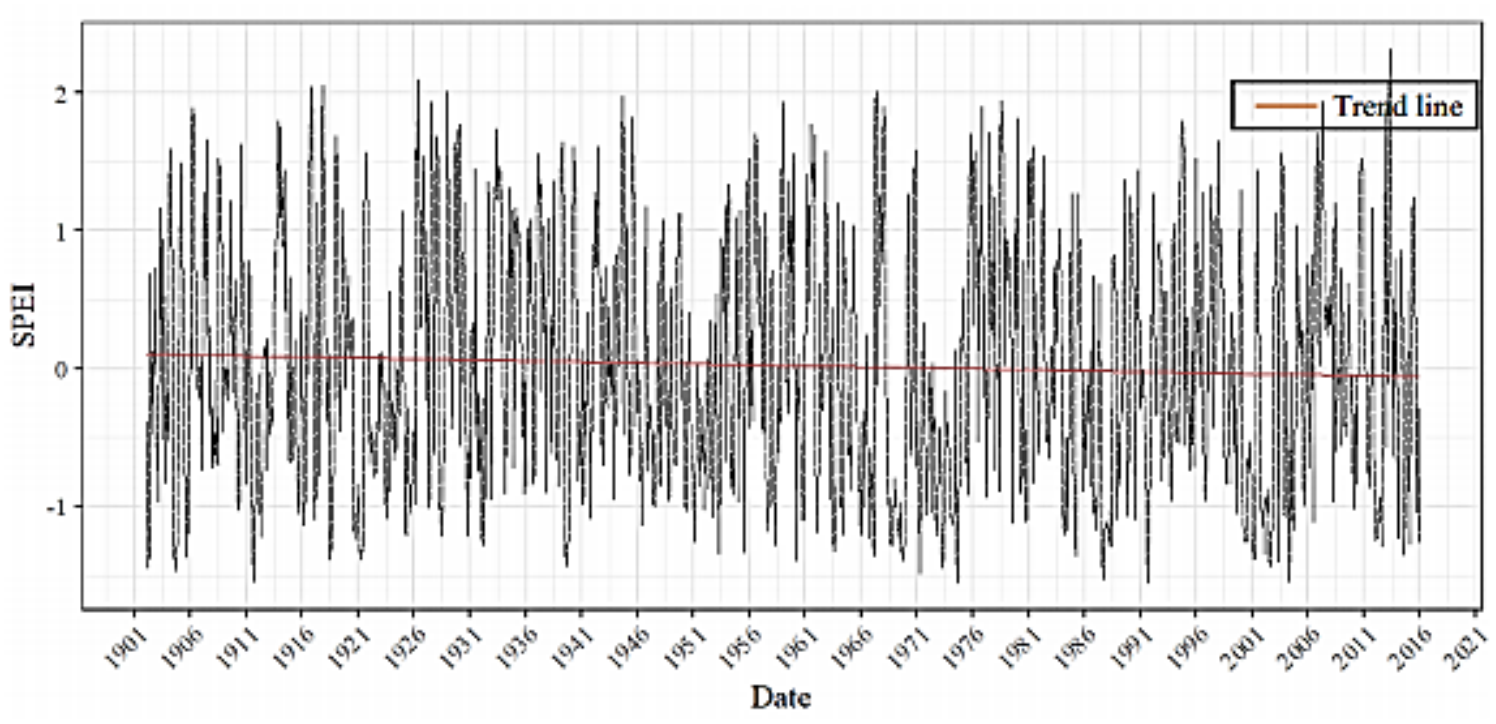

Figure 33 Months Historic SPEI
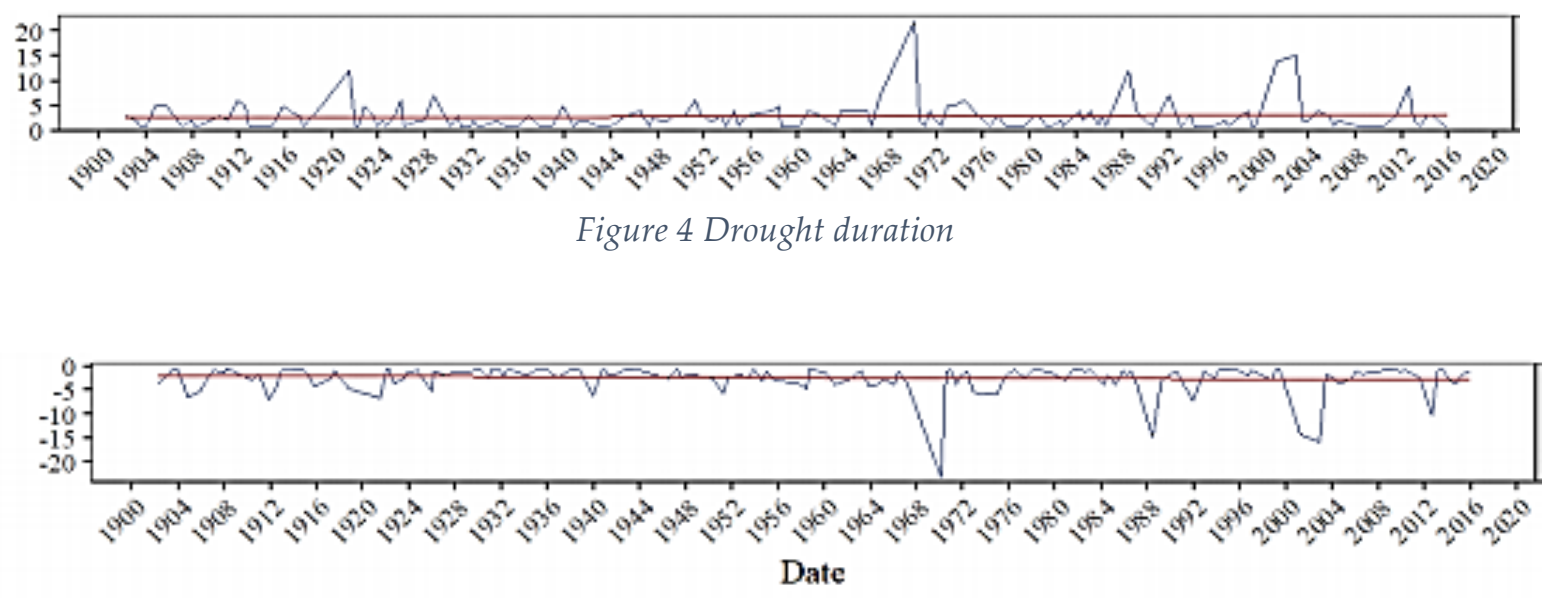

Figure 5 Drought severity

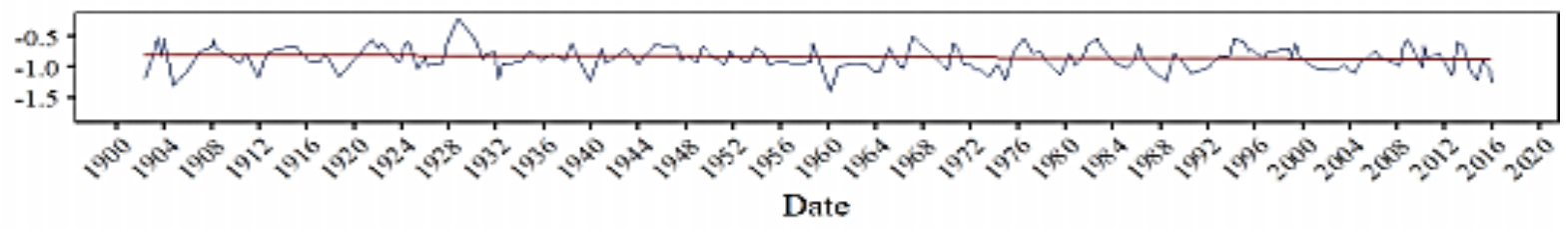

Figure ba Drought intensity

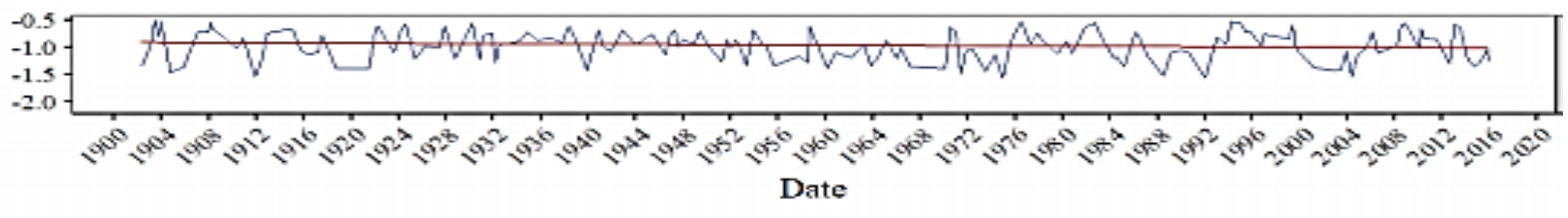

Figure 7 Drought peak 


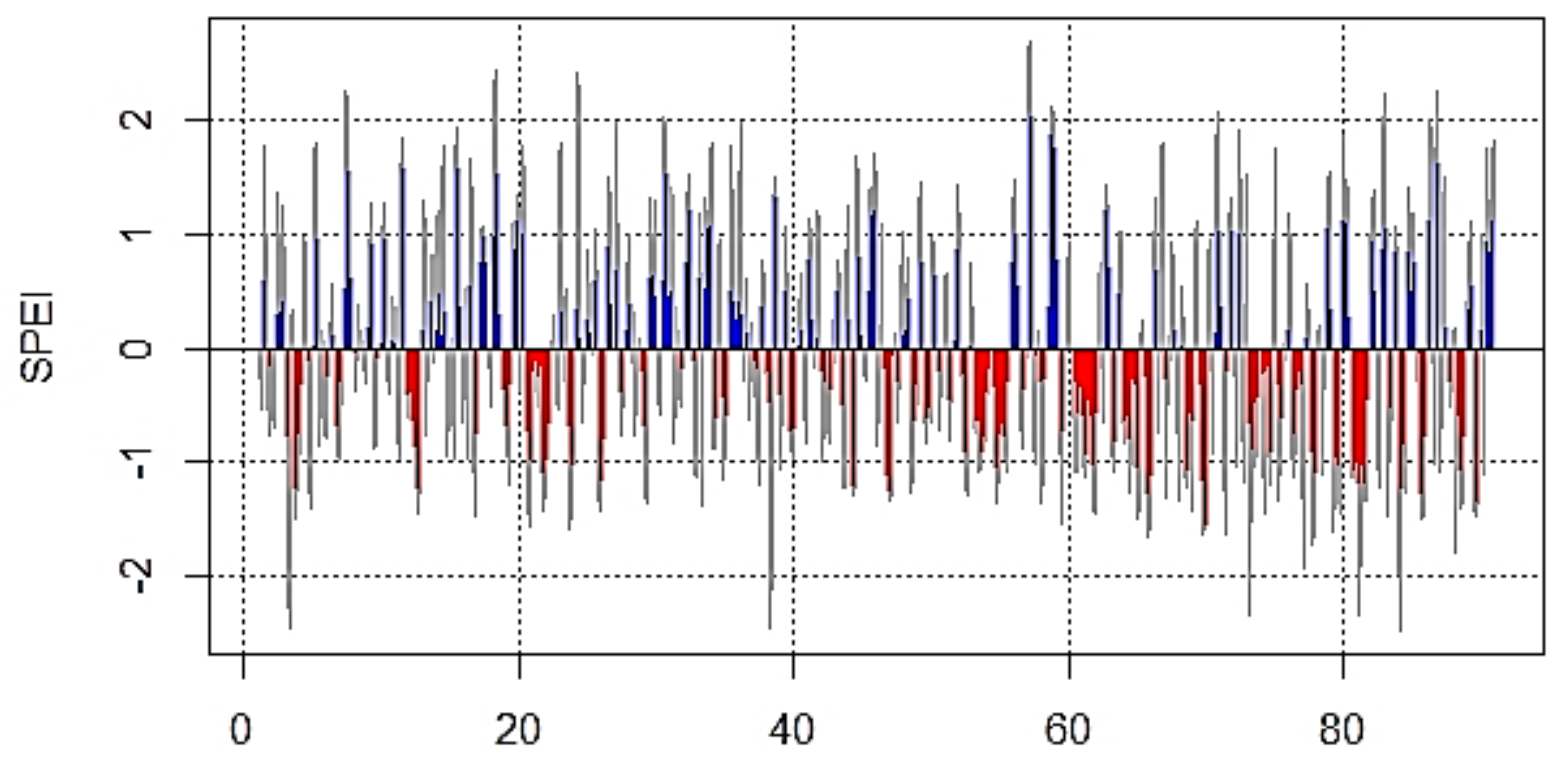

Figure 8 Projected 3 Months SPEI Index of year 2010-2099

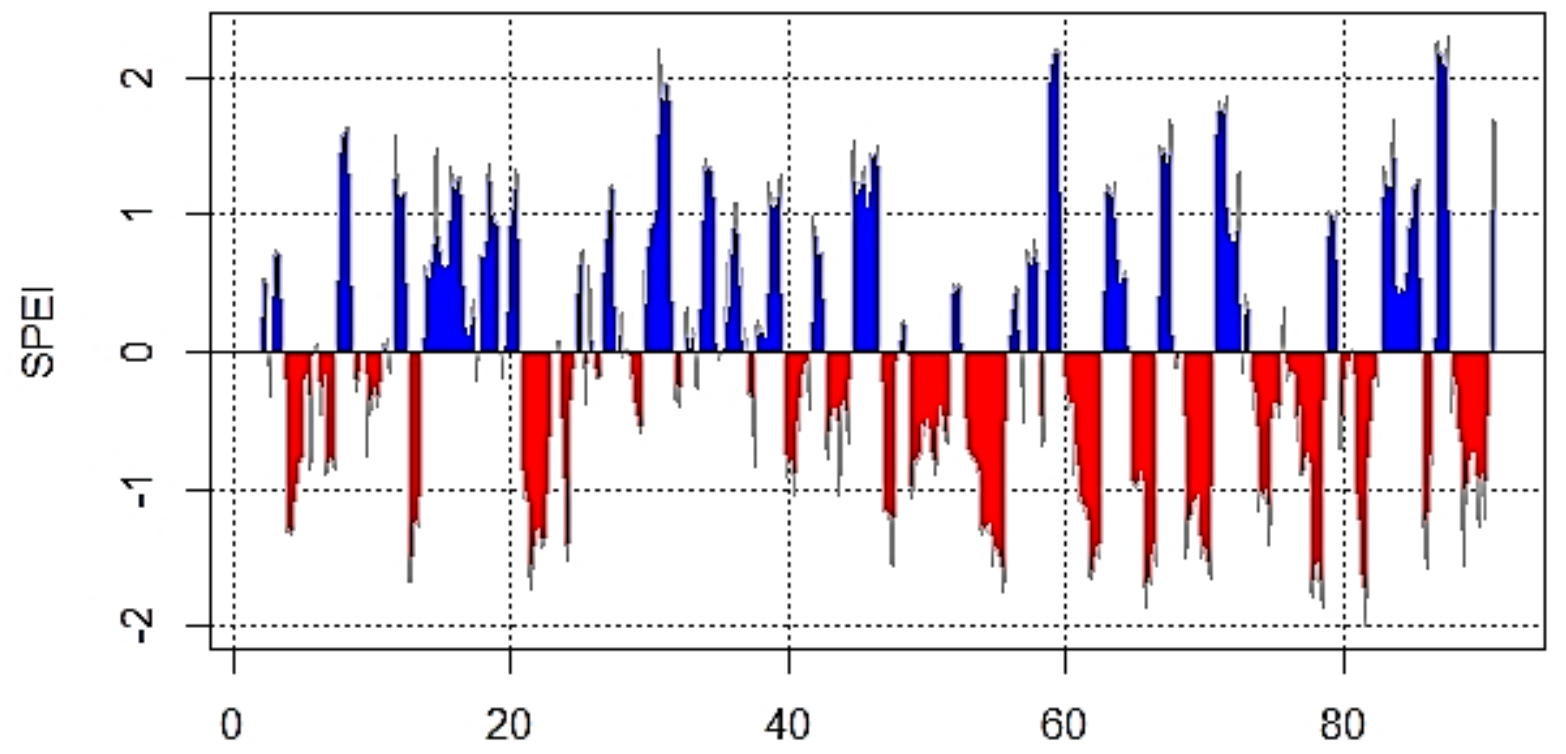

Figure 9 Projected 12 Month SPEI Index of year 2010-2099 


\section{CONCLUSIONS}

Among many natural hazards Drought is very severe hazard that will be extravagant in near future, as climate is changing day by day. Sindh Province is also one of the many affected places and is highly influenced in context of climate change. That is why, it become necessary to evaluate the pattern of droughts in Sindh to design countermeasures effectively. Hence, this research is carried out so that the pattern and occurrence of droughts can be analyzed, which will help in the behavioral understanding of drought in Sindh.

Comprehensive study extracts the variability of drought characteristics in Sindh. Due to, some limitations in data for research. SPEI is only considered for 3 months, also continent for short term modeling of meteorological drought. Also, the SPEI index for drought used in this research was extracted from a particular dataset (CRU) of precipitation and other fields related to climate [8].

\section{References}

1. Wilderspin, I., Giles, J., Hildebrand, J., Khan, M., Lizarazo, M., \& Grosjean, G. (2019). Climate-smart agriculture for disaster risk reduction in Sindh, Pakistan.

2. Nhi, P. T. T., Khoi, D. N., \& Hoan, N. X. (2019). Evaluation of five gridded rainfall datasets in simulating streamflow in the upper Dong Nai river basin, Vietnam. International journal of digital earth, 12(3), 311327.

3. Birch, E. L. (2014). A Review of "Climate Change 2014: Impacts, Adaptation, and Vulnerability" and "Climate Change 2014: Mitigation of Climate Change" Intergovernmental Panel on Climate Change.(2014).(Contribution of Working Group II to the Fifth Assessment Report of the Intergovernmental Panel on Climate Change). New York, NY: Cambridge University Press. 2,621 pages. Available online at http://ipcc-wg2. gov/AR5/report/final-drafts/; Intergovernmental Panel on Climate Change.(2014).(Contribution of Working Group III to the ....

4. Xu, C. Y., \& Singh, V. P. (2001). Evaluation and generalization of temperature-based methods for calculating evaporation. Hydrological processes, 15(2), 305-319.

5. Thornthwaite, C. W. (1948). An approach toward a rational classification of climate. Geographical review, 38(1), 55-94.

6. Abramowitz, M., \& Stegun, I. A. (1965). Handbook of mathematical functions with formulas, graphs, and mathematical table. In US Department of Commerce. National Bureau of Standards Applied Mathematics series 55.

7. Vicente-Serrano, S. M., Beguería, S., \& López-Moreno, J. I. (2010). A multiscalar drought index sensitive to global warming: the standardized precipitation evapotranspiration index. Journal of climate, 23(7), 16961718.

8. Jamro, S., Dars, G. H., Ansari, K., \& Krakauer, N. Y. (2019). Spatio-temporal variability of drought in Pakistan using standardized precipitation evapotranspiration index. Applied Sciences, 9(21), 4588. 